\title{
Design and Calibration of a Full-Scale Active Magnetic Bearing-Based Test Facility for Investigating Rotordynamic Properties of Turbomachinery Seals in Multiphase Flow
}

\author{
Voigt, Andreas Jauernik; Mandrup-Poulsen, Christian; Nielsen, Kenny; Santos, IImar
}

Published in:

Journal of Engineering for Gas Turbines and Power

Link to article, DOI:

$10.1115 / 1.4035176$

Publication date:

2017

Document Version

Peer reviewed version

Link back to DTU Orbit

Citation (APA):

Voigt, A. J., Mandrup-Poulsen, C., Nielsen, K., \& Santos, I. (2017). Design and Calibration of a Full-Scale Active Magnetic Bearing-Based Test Facility for Investigating Rotordynamic Properties of Turbomachinery Seals in Multiphase Flow. Journal of Engineering for Gas Turbines and Power, 139(5), [052505].

https://doi.org/10.1115/1.4035176

\section{General rights}

Copyright and moral rights for the publications made accessible in the public portal are retained by the authors and/or other copyright owners and it is a condition of accessing publications that users recognise and abide by the legal requirements associated with these rights.

- Users may download and print one copy of any publication from the public portal for the purpose of private study or research.

- You may not further distribute the material or use it for any profit-making activity or commercial gain

- You may freely distribute the URL identifying the publication in the public portal 


\section{DESIGN AND CALIBRATION OF A FULL SCALE ACTIVE MAGNETIC BEARING BASED TEST FACILITY FOR INVESTIGATING ROTORDYNAMIC PROPERTIES OF TURBOMACHINERY SEALS IN MULTIPHASE FLOW}

\author{
Andreas Jauernik Voigt \\ Lloyd's Register Consulting/ \\ Department of Mechanical Engineering \\ Technical University of Denmark \\ Copenhagen, Denmark \\ Email: andreas.voigt@Ir.org \\ Kenny Krogh Nielsen \\ Lloyd's Register Consulting \\ Copenhagen, Denmark \\ Email: kenny.krogh-nielsen@Ir.org
}

\author{
Christian Mandrup-Poulsen \\ Department of Mechanical Engineering \\ Technical University of Denmark \\ Copenhagen, Denmark \\ Email: cman@mek.dtu.dk
}

\begin{abstract}
The recent move towards subsea oil and gas production brings about a requirement to locate process equipment in deepwater installations. Furthermore, there is a drive towards omitting well stream separation functionality, as this adds complexity and cost to the subsea installation. This in turn leads to technical challenges for the subsea installed pumps and compressors that are now required to handle multiphase flow of varying gas to liquid ratios. This highlights the necessity for a strong research focus on multiphase flow impact on rotordynamic properties and thereby operational stability of the subsea installed rotating machinery. It is well known that careful design of turbomachinery seals, such as interstage and balance piston seals, is pivotal for the performance of pumps and compressors. Consequently, the ability to predict the complex interaction between fluid dynamics and rotordynamics within these seals is key. Numerical tools offering predictive capabilities for turbomachinery seals in multiphase flow are currently being developed and refined, however the lack of experimental data for multiphase seals renders benchmarking and validation impossible. To this end, the Technical University of Denmark and Lloyd's Register Consulting are currently establishing a purpose built state of the art multiphase seal
\end{abstract}

test facility, which is divided into three modules. Module I consists of a full scale Active Magnetic Bearing (AMB) based rotordynamic test bench. The internally designed custom AMBs are equipped with an embedded Hall sensor system enabling highprecision non-contact seal force quantification. Module II is a fully automatised calibration facility for the Hall sensor based force quantification system. Module III consists of the test seal housing assembly. This paper provides details on the design of the novel test facility and the calibration of the Hall sensor system employed to measure AMB forces. Calibration and validation results are presented, along with an uncertainty analysis on the force quantification capabilities.

${ }^{*}$ Address all correspondence to this author. 


\section{NOMENCLATURE}

B

$\Delta y$

$\Omega$

C

$c$

EM

$F_{a c t}$

$F_{a p p, y}, F_{a p p, z}$

$F_{A, y}, F_{A, z}$

$F_{B, y}, F_{B, z}$

$F_{c, y}, F_{c, z}$

$F_{K_{H}}$

$F_{y}, F_{z}$

Ibias

K

$k$

$K_{a}, K_{b}, K_{c}, K_{d}$

$M$

m

$u$

$M_{c, y}, M_{c, z}$

$V_{H}, V_{H, N}, V_{H, S}$

AMB

CFD

FBD

GVF

LVF

I/O

IPM

MAE

PCB

PID

PWM

SISO

VSD
Magnetic flux density [T]

Rotor displacement from rotor offset [m]

Rotational velocity of shaft [rpm]

Direct seal damping $[\mathrm{Ns} / \mathrm{m}]$

Cross coupling seal damping $[\mathrm{Ns} / \mathrm{m}]$

Electromagnet

AMB actuator forces [N]

Calibration forces $[\mathrm{N}]$

AMB A force components [N]

AMB B force components [N]

Coupling force components [N]

Force estimated by Hall sensor system [N]

Seal reaction force components [N]

AMB bias current $[\mathrm{A}]$

Direct seal stiffness $[\mathrm{N} / \mathrm{m}]$

Cross coupling seal stiffness [N/m]

Hall sensor calibration constants [N/V]

Direct seal inertia $[\mathrm{kg}]$

Cross coupling seal inertia [kg]

Error

Coupling moment components [Nm]

Hall voltage signal [V]

Active Magnetic Bearing

Computational Fluid Dynamics

Free Body Diagram

Gas Volume Fraction

Liquid Volume Fraction

Input/Output

Instationary Perturbation Method

Mean Absolute Error

Printed Circuit Board

Proportional-Integral-Derivative

Pulse-Width Modulation

Single-Input Single-Output

Variable Speed Drive

\section{Introduction}

The energy sector is dependent on high pressures, small clearances, and high rotational velocities in compressors and pumps to ensure a high productivity. However, the range of rotational velocities is restricted by the stability margins of the rotating machinery $[1,2]$. It is well known that the rotordynamic forces generated by the interaction of process fluid, rotor and seals are of primary importance for the rotordynamic stability and thereby operability and life span of the rotating machinery employed in the energy sector today $[3,4]$, rendering seals a very important subject of study.

A significant amount of research has been done over the last 40 years to identify the rotordynamic properties of seals subdued

to single-phase flows, both theoretically and experimentally, in order to ensure the very important predictive capabilities for seal dynamics through mathematical modelling [4-27]. However, as highlighted in the survey presented by Kocur, et al. [28], there is still work to be done. Kocur, et al. found, among other, very large variations in rotordynamic coefficients for gas labyrinth seals predicted by survey participant from both academia and industry.

As oil and gas reserves presently in production deplete, the global oil and gas industry continues to move towards production from fields at greater sea depth and in the Arctic regions. The production from many of these fields requires compression and pumping to take place on the sea floor where the possibility of performing liquid and gas separation on the well stream is very limited. Consequently, the subsea installed pumps and compressors have to cope with streams that cannot be considered single-phase. Multiphase fluid mixture will have significantly different fundamental properties [29] as compared to single-phase fluids, and therefore the modelling of the multiphase seal flow impact on rotordynamics requires special treatment.

As indicated above the research on single-phase seal rotordynamics is well established. However, the research on multiphase seal rotordynamics is presently only in its infancy [30-34]. The experimental validation of existing mathematical models is in particular insufficient. An improved understanding of the underlying assumptions and limitations of these models is necessary to further justify their usage, which only rigorous experimental testing and comparison with theoretical results will provide. The focus of this paper is to present a newly developed test facility for testing seals subdued to both single- and multiphase flow conditions. The paper contains a presentation of the different modules of the test facility as well as a calibration of the main functionality of the test facility. The underlying work presents the status of the experimental research branch of the ongoing collaboration between the Technical University of Denmark (DTU), Lloyd's Register Consulting (LRC), OneSubsea, TOTAL and Statoil. This research venture was initiated to ensure validated predictive capabilities through state of the art Computational Fluid Dynamics (CFD) benchmarked using high quality experimental data. The state of the art regarding determination of rotordynamic coefficients for seals in multiphase flow using CFD can be found in [35].

\section{Baseline functionality considerations for the test facil- ity design}

The multiphase seal test facility is designed to enable component level experimental identification of rotordynamic properties of turbomachinery seals. The test results are to be used for benchmarking and performance evaluation of Computational Fluid Dy- 
namics (CFD) based numerical tools as well as bulk flow models used for theoretical prediction of seal properties. The functional principle of the test facility adheres to the group conventional parameter identification schemes for rotordynamic components, which is based on frequency dependent time domain perturbation of the seal flow. The goal of the identification scheme is to extract stiffness, damping, and where relevant, inertia properties of seals subdued to both single- and multiphase flow. For rotordynamic modelling purposes it is conventional to cast the seal model in the following form [3], assuming frequency dependent coefficients and neglecting inertia effects

$$
-\left\{\begin{array}{l}
F_{z} \\
F_{y}
\end{array}\right\}=\left[\begin{array}{cc}
K(\Omega) & k(\Omega) \\
-k(\Omega) & K(\Omega)
\end{array}\right]\left\{\begin{array}{l}
z \\
y
\end{array}\right\}+\left[\begin{array}{cc}
C(\Omega) & c(\Omega) \\
-c(\Omega) & C(\Omega)
\end{array}\right]\left\{\begin{array}{l}
\dot{z} \\
\dot{y}
\end{array}\right\}
$$

The test facility is designed to be able to mirror the Instationary Perturbation Method (IPM) applied for numerical estimation of seal properties using CFD. This method is described in detail in [26, 35-38], and relies on perturbing the seal flow by moving the shaft in a prescribed 1D sinusoidal pattern with a constant amplitude and for multiple frequencies. Acquiring information on the reaction forces exerted on the seal rotor allows the coefficients of Eqn. 1 to be determined by applying simple time domain identification techniques [26]. Active Magnetic Bearings (AMBs) are very well suited to provide the necessary perturbation functionality, and it should be mentioned that the AMBs allow for much more sophisticated perturbation patterns and thereby identification techniques, than the baseline functionality discussed above.

The forces exerted on the seal rotor from perturbing the seal flow need to be quantified with high precision and reliability to allow for identification of the rotordynamic seal properties. The AMB readily facilitates force estimation through measurement of the AMB coil currents and knowledge of the shaft position within the AMB. This method is referred to as the $(i-s)$ methodology in the literature [39]. However, it has been shown that higher force estimation precision can be achieved by employing Hall sensors mounted in the pole surface areas of the AMBs $[40,41]$ as compared to the $(i-s)$ method. Additionally, low force estimation errors have been reported using fiber optic strain gauges [42-44], giving merit to a continued research effort. However, the relatively low level of experience with this method reported in the literature, and the fact that it is susceptible to calibration drift [42], makes it less proven than the two previously outlined force estimation approaches.

Conventional placement of Hall sensors in AMB poles requires enlargement of the air gap between rotor and stator in the AMBs consequently reducing the load bearing capacity of the AMB system. To accommodate this the test facility have been designed with a Hall sensor system where the Hall sensors are completely embedded into the pole surface, a method previously employed with success in stand-alone AMBs used for excitation purposes $[41,45]$. This test facility is the first to feature a shaft completely radially supported by two AMBs with embedded Hall sensors. To achieve the desired precision needed to perform experimental identification of seal rotordynamic properties it is of paramount importance that the Hall sensor system is calibrated in-situ, which is the focus of the last part of this paper. Additionally, it is essential for identification purposes that the relative motion of the seal rotor to the seal stator is precisely determined. High-precision position data (uncertainty including noise below $1 \mu \mathrm{m}$ ) is readily available from the AMBs, as these inherently features position sensors needed for feedback control. Calibration of the position sensors are not discussed further in this paper.

\section{Multiphase seal test facility}

The test facility is comprised of three modules: (1) An AMB based rotordynamic test bench, (2) a calibration module for the Hall sensor system, and (3) a test seal housing assembly and multiphase flow loop. It should be mentioned that the calibration module and the seal housing assembly replaces each other, and cannot be installed on the test bench simultaneously. The individual modules are introduced in the following sections.

\section{Module I}

A picture of the test facility in its calibration configuration is presented in Fig. 1, in which both Module I and II are visible. The picture shows the main elements of Module I, namely: The two radial AMBs, the shaft assembly, the asynchronous motor, the intermediate shaft pedestal, and the flexible coupling. The main shaft is supported radially by the AMBs and axially by the intermediate shaft through a flexible disc coupling. The intermediate shaft sits in high-speed angular contact ball bearings within the intermediate shaft pedestal. The $7.5 \mathrm{~kW}$ three-phase asynchronous motor is controlled through a Variable Speed Drive (VSD) unit and drives the intermediate shaft, and thereby the main shaft, through a timing belt interface. The timing belt pulleys on the motor and intermediate shaft can be changed to achieve the wanted rpm range for the main shaft. At the motor end of the intermediate shaft an encoder is attached through a flexible multibeam coupling (not visible on Fig. 1). The encoder provides precise information on shaft speed and angular position, the latter being important for runout compensation purposes. The main shaft assembly parameters are summarized in Table 1. The shaft is symmetric and can be considered rigid within the operational frequency range of the test facility with its first bending mode at $550 \mathrm{~Hz}$. The main component of the AMB rotor assemblies are made from laminated electrical steel 


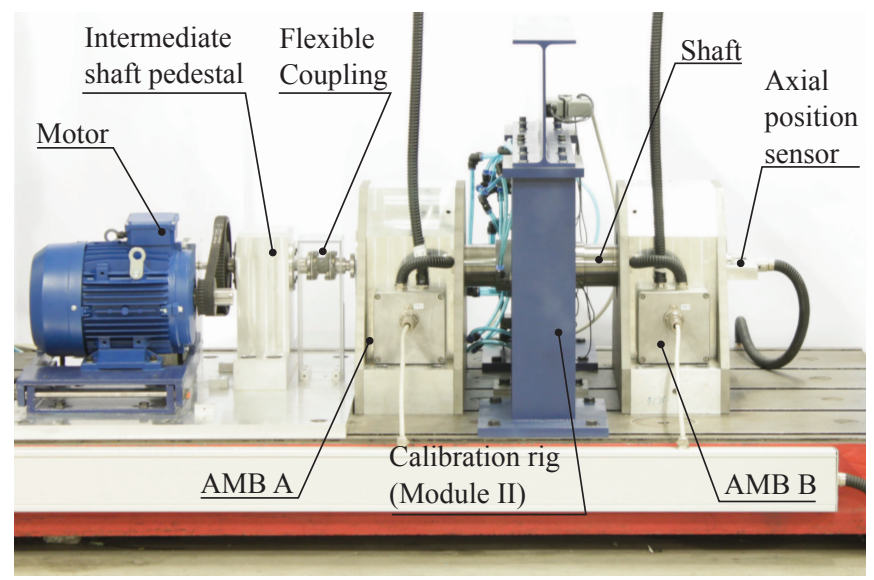

FIGURE 1: Test facility in calibration configuration

sheets identical to that of the AMB stators, and the assemblies are mounted onto the main shaft through an interference fit.

The hub component of Module I is the radial eight pole heteropolar AMB depicted in Fig. 2 without its cover plates to reveal the internal layout. The AMB design parameters are presented in Table 2. Each AMB features three main component groups visualized in a section view on Fig. 3: (1) The support structure is indicated with a blue hatched pattern in Fig. 3. The support structure consists of a main aluminium body bolted onto an aluminium base and two $20 \mathrm{~mm}$ thick stainless steel plates bolted onto each side of the AMB to provide transversal stiffness to the assembly. (2) The backup bearing assembly is indicated with a red hatched pattern on Fig. 3. The backup bearing assembly features a set of grease lubricated high-precision high-speed angular contact ball bearings. These are mounted in a back-to-back configuration to account for axial loads during a potential shaft drop. The backup bearings are seated in a compliant ring design that facilitates dissipation of energy during a shaft drop. The backup bearing assembly also houses the primary AMB sensor system consisting of two high-precision inductive VibroMeter position probes used for feedback control. (3) The AMB stator assembly, which is indicated with a green hatched pattern on Fig. 3. The stator laminates, made from SURA M270-35A high quality electrical steel, are sandwiched in between two retention plates and held together by bolt connections. The stator design adopts the conventional tilted design [39] where the axes of the magnetic bearing actuators are shifted $45^{\circ}$ so that two electromagnets can be engaged to account for the gravitational load of the shaft. On the back of the stator assembly the interface Printed Circuit Board (PCB) board for the Hall sensor system is positioned. The Hall sensors are cemented into tracks in each of the eight pole legs of the stator. The Hall sensor placement can be seen
TABLE 1: Main shaft parameters

\begin{tabular}{lrl}
\hline Shaft length & 860 & $\mathrm{~mm}$ \\
Shaft assembly mass & 69 & $\mathrm{~kg}$ \\
AMB rotor outer diameter & 150 & $\mathrm{~mm}$ \\
Test seal rotor diameter & 110 & $\mathrm{~mm}$ \\
First bending mode @ & 550 & $\mathrm{~Hz}$ \\
Lamination thickness & 0.35 & $\mathrm{~mm}$ \\
Number of laminations & 228 & \\
Laminate material & SURA M270-35A & \\
\hline
\end{tabular}

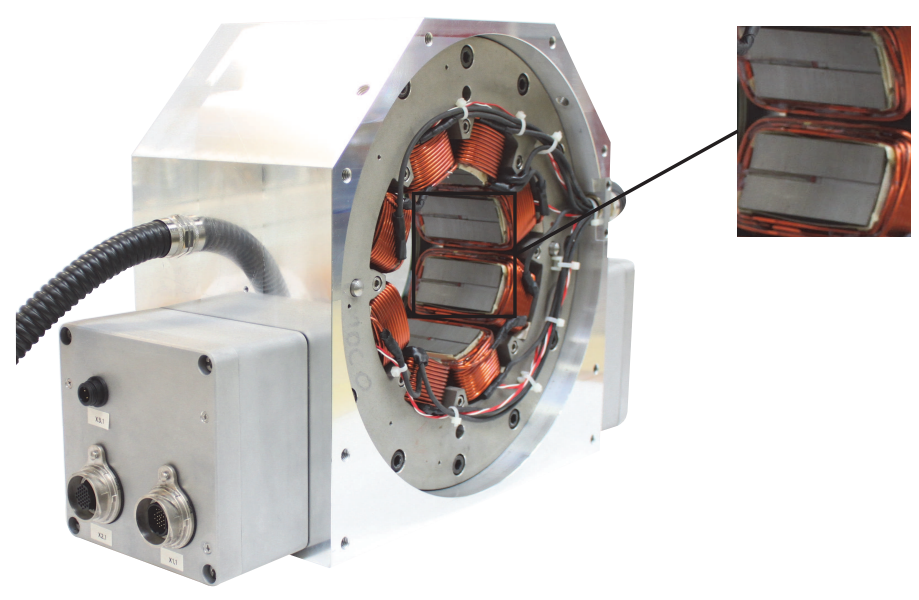

FIGURE 2: A view of the test facility AMB design showing the embedded Hall sensor placement in a zoom view

on the zoom view of Fig. 2. Embedding the Hall sensors keeps the fragile sensors protected, at the cost of a slightly reduced effective pole area. This reduces the maximum force obtainable from the AMBs, however the effect is minimal and has been determined to be in the order of $2 \%$, which is consistent with previous findings [45]. The Hall sensor supply and signal leads are soldered onto the interface PCB board from which the Hall sensor signal is fed to the signal amplifier situated on the side of the AMB main housing. Amplification and signal conditioning of the Hall sensor signals close to the sensor helps keep noise contamination of the signals to a minimum and thereby the signal to noise ratio high. Both the Hall sensor constant current supply and the amplification circuits have been custom built for the test facility.

The AMBs are designed to be operated in differential mode [39] and feedback based position control of the shaft is currently achieved through a decentralized Single-Input Single-Output (SISO) control structure. The baseline controller is a conven- 
TABLE 2: AMB design parameters

\begin{tabular}{lrc}
\hline Stator outer diameter & 300 & $\mathrm{~mm}$ \\
Stator inner diameter & 151 & $\mathrm{~mm}$ \\
Nominal radial air gap & 0.5 & $\mathrm{~mm}$ \\
Pole width & 40 & $\mathrm{~mm}$ \\
Pole depth (axial) & 80 & $\mathrm{~mm}$ \\
Number of poles & 8 & \\
Winding configuration & N-S-S-N-N-S-S-N & {$[-]$} \\
Lamination thickness & 0.35 & $\mathrm{~mm}$ \\
Number of laminations & 228 & \\
Laminate material & SURA M270-35A & \\
Number of coil windings & 36 & \\
Coil wire thickness & 2.8 & $\mathrm{~mm}$ \\
Max. load capacity (per AMB) & 7500 & $\mathrm{~N}$ \\
Bias current range & 4 to 10 & A \\
Coil temp. sensor type & PT100 & \\
Number of temp. sensors & F.W. Bell - FH-301 & \\
Number of Hall sensors & $2.54 \times 3.175 \times 0.5$ & $\mathrm{~mm}$ \\
Hall sensor type & & \\
Hall sensor dimensions $(l \times w \times h)$ & & \\
\hline
\end{tabular}

tional Proportional-Integral-Derivative (PID) controller, however the system can also be operated using a robust $H_{\infty}$ controller. The controllers are embedded on a modular dSPACE I/O system that facilitates control and data acquisition for the entire test facility. The AMBs are supplied by eight $3 \mathrm{~kW}$ high-speed Pulse-Width Modulation (PWM) mode power amplifiers from Delta-Elektronika. The high level of controllability enables the AMBs to support the shaft, while perturbing the lateral motion of the shaft in an arbitrary pattern, which is needed for seal parameter identification.

\section{Module II}

The calibration facility consists of two features: (1) The calibration rig shown in Fig. 4 and (2) the calibration clamp seen on Fig. 5. The calibration clamp is clamped around the shaft, and while mounted, the rotation of the shaft is restricted. The calibration facility enables applying a controllable multi-directional load onto the shaft, which is accomplished through a set of four pneumatic pistons. Each individual piston can be electronically controlled through the dSPACE I/O interface both in terms of actuation direction and force magnitude. The magnitude of the applied force is controlled using a PD regulated proportional valve. The force from the pistons is transferred to the shaft by a grabbing device engaging with a set of Belleville springs that transfers the force

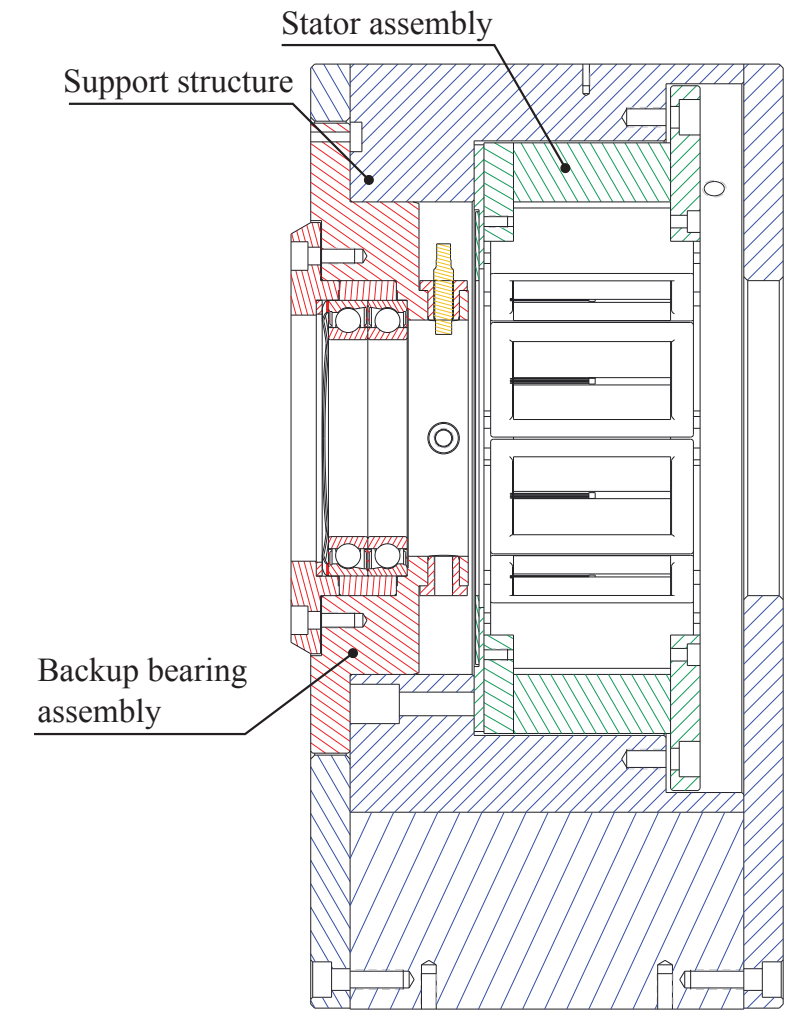

FIGURE 3: Section view of AMB showing three main component groups

to a high-precision HBM U9C force transducer in order to measure the imposed load. The grabbing device, seen in Fig. 5, is designed such that when a piston is parked in its most extended position, there is no contact between the calibration rig and the shaft, thus reducing force contamination in the calibration procedure. Additionally the grabbing device allows for misalignments thus reducing bending moments over the force transducer and thereby reducing erroneous force measurements during calibration. The highly controllable calibration facility enables complete automation of the calibration procedure for multiple load directions and shaft positions.

\section{Module III}

Module III is comprised of two main parts: the seal housing assembly and the multiphase flow loop, treated separately in the following.

Seal housing assembly The seal housing assembly is presented in Fig. 6 showing the inlet cavity and nozzles, the outlet feature containing the primary and secondary flow outlets, mounting holes for the pressure transducers, the test seal lands, and the support structure. The seal housing assembly adopts 


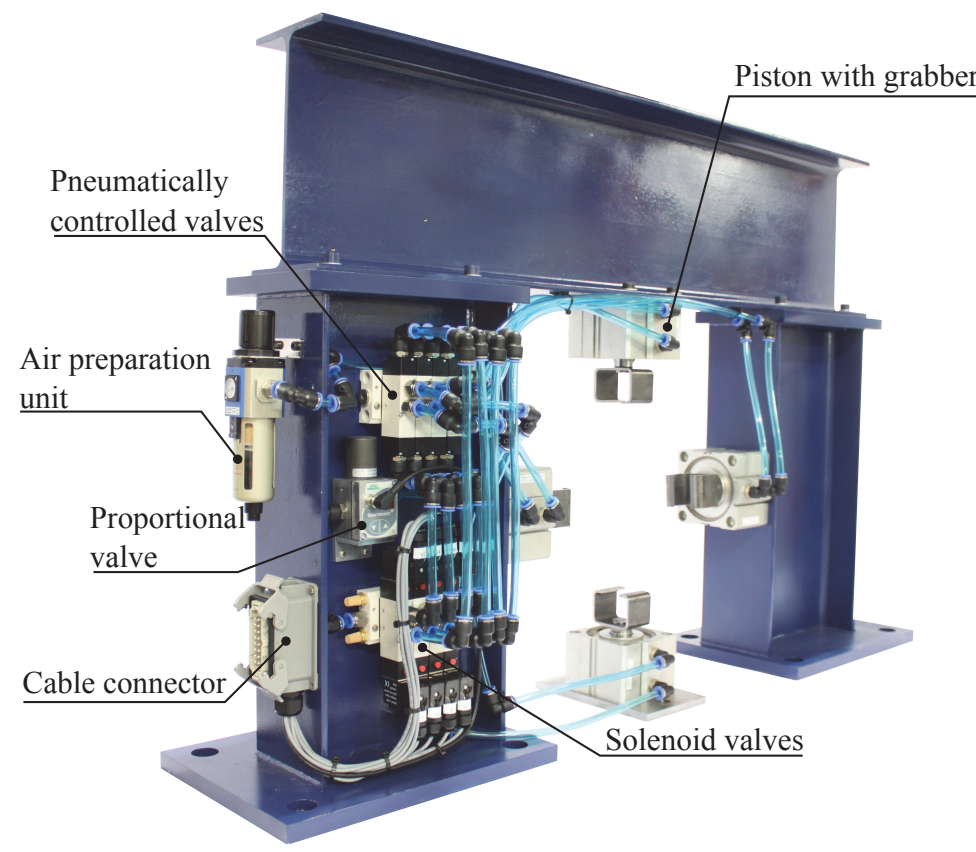

FIGURE 4: Calibration rig showing pneumatic pistons, grabbing device and control features

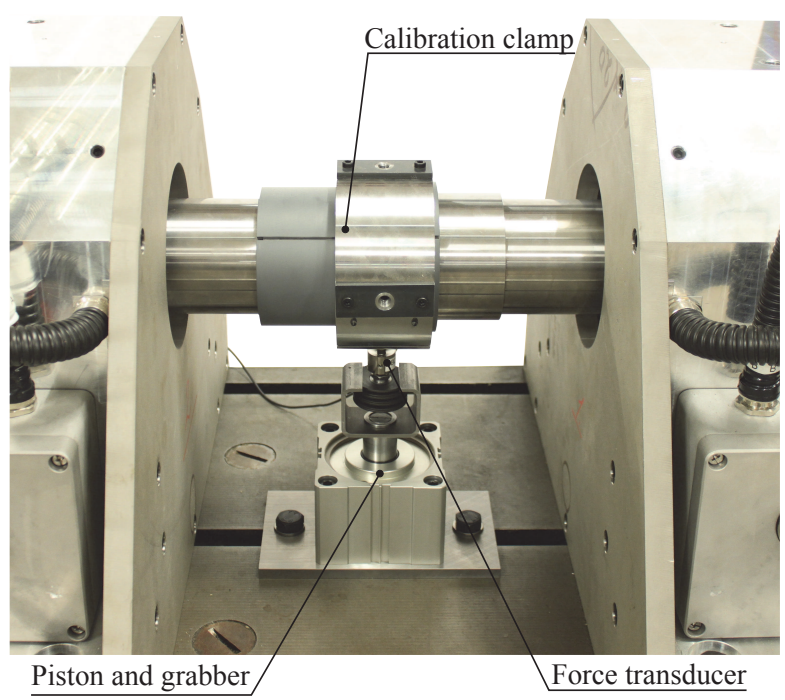

FIGURE 5: Simplified calibration setup showing calibration clamp, single piston with grabber, and force transducer

the modular design of the AMBs and is made in a split design to ease assembly. The flow medium is injected into the seal housing assembly through nozzles placed in the centre of the seal housing assembly and enters the two symmetrical test seals machined from a solid block of aluminium in a back-to-back

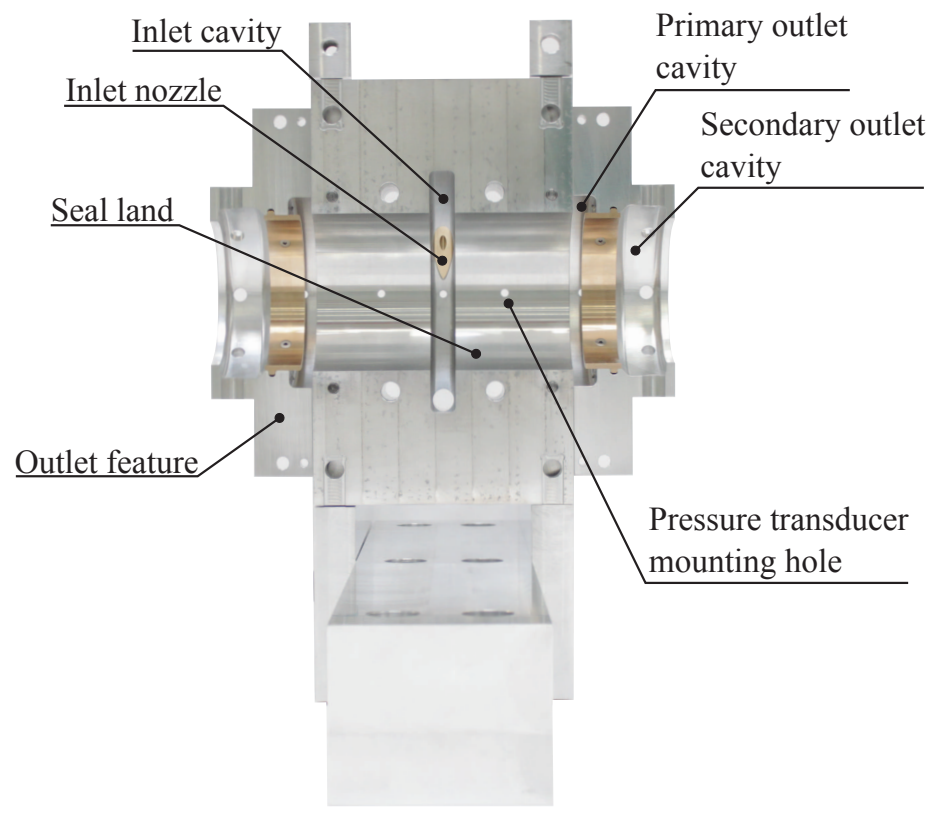

FIGURE 6: Half part of seal housing assembly showing inlet and outlet features

configuration to alleviate axial thrust. After the flow has passed the seal lands, it exits in a controlled manner through two outlet features. Smooth annular seals have been chosen as initial test seal configurations since their simple geometry and well known single-phase performance constitutes a good choice for benchmarking the capabilities of the test facility initially.

A section view of the centre of the inlet cavity is presented in Fig. 7, which shows the symmetrical distribution of the four inlet nozzles as well as the two mounting holes for the inlet pressure transducers. In this initial iteration of the seal housing assembly design the pre-swirl is fixed and cannot be adjusted mechanically but only by changing injection flow velocity through modifying the nozzle geometry. As evident from the almost tangential injection direction, the seal housing assembly is aimed at testing seals in the high pre-swirl range. The nozzles are held in place by a flow adapter component, which additionally interfaces with the flow supply lines.

Since the test facility is designed to handle both pure gaseous, pure liquid and multiphase flows, the seal housing assembly outlet features require special attention, as it cannot be assumed that the flow can be exhausted to atmospheric conditions. Additionally, the wish to be able to run the test facility with significant back-pressures entails that secondary sealing capabilities should be included in the design. Using conventional secondary seals for the outlet, e.g. labyrinth seals, gives rise to 
potential contamination of the test results as the secondary seals will produce radial forces similarly to the main test seals. The outlet feature design aims at avoiding the issue of contaminating radial forces from secondary seals.

The test facility outlet feature is shown in Fig. 8. The outlet feature has two sequential outlets, referred to as the primary and the secondary outlet, respectively. The primary outlet consists of eight circumferentially distributed outlet ports, four on each outlet feature half part, as shown on Fig. 8. Valves on the primary outlet ports can be adjusted to apply back-pressure to the seal flow (not shown). Any flow that does not follow the primary flow path passes through the secondary flow path into the secondary outlet cavity and exits through the secondary outlet ports or as leakage flow along the shaft. The main advantage of the outlet design is that sealing takes place between axially oriented surfaces in the secondary flow path between the shaft and the outlet feature lip, see Fig. 8. This entails that there will be no contaminating radial forces from the outlet feature since all radial clearances are kept at least a factor of two larger than the test seal clearance. To verify performance of the outlet feature design a full 3D Computational Fluid Dynamic (CFD) based performance validation study was conducted. The study found that for medium to high pressure ratios over the test seals, the flow in the primary flow path creates a Venturi ejector effect when passing the secondary flow path clearance, reversing the flow in the secondary flow path, effectively eliminating leakage flow. This phenomenon has been observed for a back-pressure of up to 10 bar at an inlet pressure of 40 bar for both single-phase water and air conditions.

The seal housing assembly is instrumented with Kistler piezo-resistive absolute pressure sensors of the type 4065B. These sensors measure absolute and dynamic pressure as well as temperature of the flow in the range from 0 to 200 bar. The mounting holes for the sensors can be seen in Fig. 9, along with an overview of the seal housing assembly main components in its seal testing configuration. The Kistler probes enable measuring the inlet and outlet cavity pressures and temperatures, as well as the pressure and temperatures of the flow within the seal lands. These measurements are valuable for comparison with simulated CFD results in the validation phase. In Table 3 key parameters for the seal housing and the test facility in general are summarized.

Flow loop The test facility is designed to operate with air and water flows. For run-in purposes the test facility will be supplied with a single-phase air flow in order to benchmark the rotordynamic seal properties identification capabilities of the test facility. The flow supply for the seal housing assembly consists of two separate supply strings for the two fluids. For multiphase operating conditions a mixing device is included upstream to the

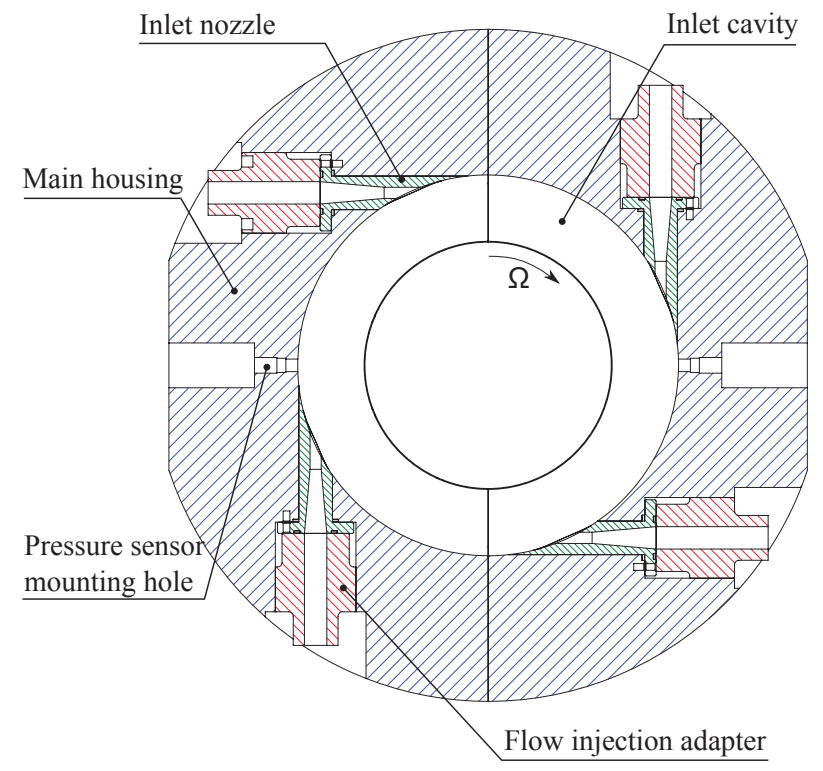

FIGURE 7: Section view of the centre of the inlet cavity showing inlet nozzle distribution and orientation as well as pressure sensor mounting holes

TABLE 3: seal housing and overall test facility key parameters

\begin{tabular}{lrl}
\hline Inlet cavity diameter & 150 & $\mathrm{~mm}$ \\
Inlet cavity width & 18 & $\mathrm{~mm}$ \\
Nominal radial seal clearance & 0.4 & $\mathrm{~mm}$ \\
Seal axial length & 83 & $\mathrm{~mm}$ \\
Axial lip clearance in secondary flow path & 0.4 & $\mathrm{~mm}$ \\
Secondary flow path radial clearance & 0.8 & $\mathrm{~mm}$ \\
Total number of primary outlet ports & 16 & \\
Total number of secondary outlet ports & 16 & \\
Maximum number of pressure/temp. sensors & 10 & \\
\hline Rotational velocity range & $0-10$ & $\mathrm{krpm}$ \\
Perturbation frequency range & $0-250$ & $\mathrm{~Hz}$ \\
Calibrated force measurement range & $0-4$ & $\mathrm{kN}$ \\
Air (single-phase) max. supply pressure & 65 & $\mathrm{bar}$ \\
Water (single-phase) max supply pressure & - & \\
\hline
\end{tabular}

inlet injections nozzles of the seal housing assembly. Different sparger and injection nozzle based mixing devices are considered able to achieve homogeneous fluid mixtures for a large range of both Gas Volume Fractions (GVFs) and Liquid Volume Fractions (LVFs). The air supply string consists of a piston compressor supplying up to 65 bar to a $3 \mathrm{~m}^{3}$ pressure tank through a series 

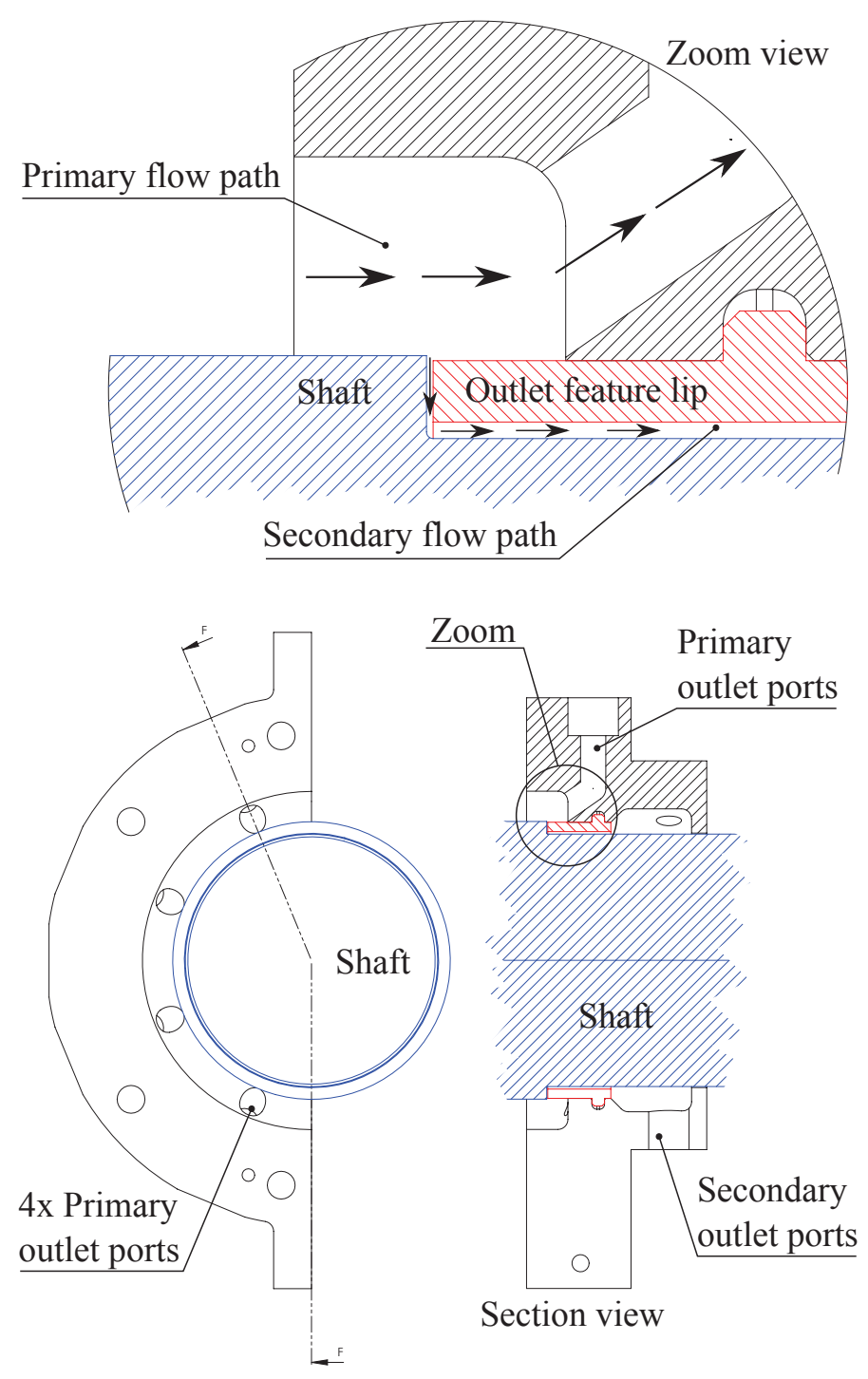

FIGURE 8: Visualization of outlet feature details

of filters ensuring dry gas conditions. The supply from the tank to the seal housing assembly is controlled by a regulator valve, capable of maintaining a stable output pressure though a supply pressure drop is experienced during tests. The water supply is designed in two iterations. The first accommodates wet gas testing for LVFs between 0 and $5 \%$, keeping the complexity, size and costs of the water supply to a minimum while still being able to attain multiphase seal test functionality of the test facility. For this setup the leakage flow containing water can be exhausted directly to a drain, eliminating the need for a separation unit and recycling of the water. The water supply for the first iteration is based around a high-pressure centrifugal pump, which matches

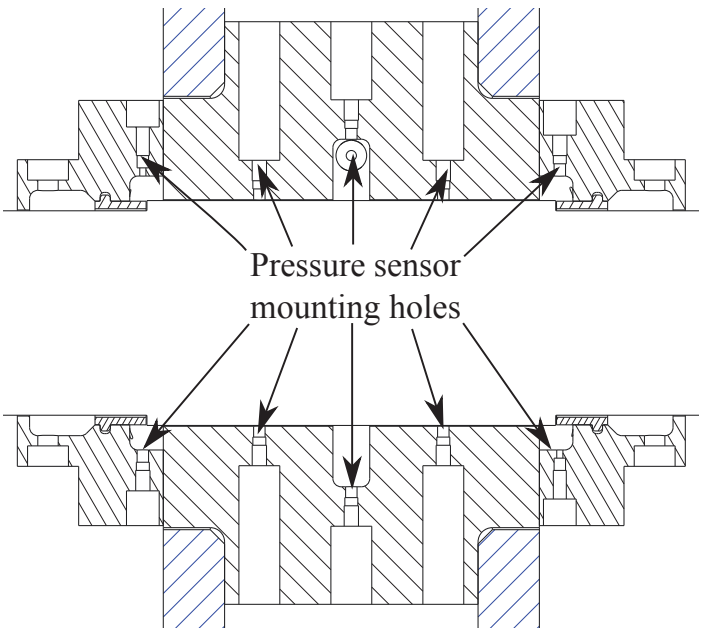

FIGURE 9: Horizontal section view of the seal housing assembly

the pressure of the air supply. The second iteration of the water supply incorporates upstream water reservoir, filtering units, high capacity pumping system and de-aeration unit for water recycling. The second iteration is currently in the design phase.

\section{Hall sensor calibration methodology}

The basic principle of the calibration procedure is to apply a known load to the centre of the shaft using the pneumatic pistons of the calibration facility and record the Hall sensor signals from all sensors. In addition to the Hall sensor signals the current signals, shaft position, and applied load are recorded simultaneously during calibration. Since the Hall sensors are embedded into the pole surface of the AMBs, it is necessary to determine if there is any significant position dependence of the calibration results [41]. However, a static calibration procedure will suffice even for dynamic force measurement purposes [41].

As mentioned earlier the force from the AMBs can in general be determined based on either Hall sensor signals or current/air gap measurements [40]. Both methods require calibration to yield precise force estimations. For a description of the force quantification method using current/air gap measurements, see e.g. [46]. The force estimation results from utilizing the two methods will be included in the result section, however since the calibration procedure is similar for both methods it will be outlined for the Hall sensor system here. The theory of measuring electromagnetic force from AMBs using Hall sensors can be found in e.g. [41], however it is important to note that the Hall sensors measure magnetic flux density $\mathbf{B}$ and produce an analogue voltage proportional to $\mathbf{B}$. The magnetic flux density $\mathbf{B}$ can then be related to the force acting on the AMB rotors. The layout of the electromagnetic 


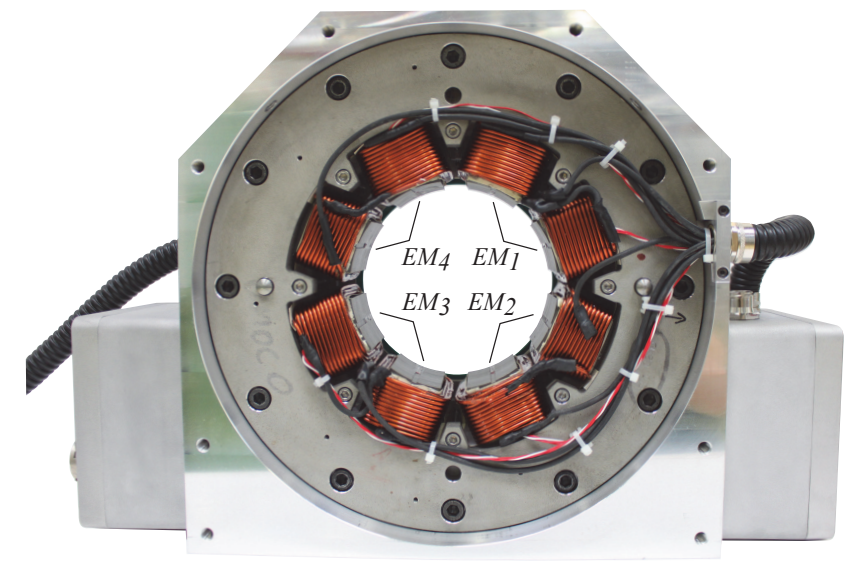

FIGURE 10: AMB stator front view showing electromagnet layout

actuators in the test facility AMB design can be seen in Fig. 10. Since the electromagnetic actuators can only exert a pulling force on the AMB rotors, the individual electromagnets are coupled in pairs to yield a dual acting electromagnetic actuator and operated using conventional differential driving [46]. The electromagnets $E M_{1}$ and $E M_{3}$, and $E M_{2}$ and $E M_{4}$ are paired together, respectively. Each electromagnet constitutes a closed electromagnetic circuit together with the AMB rotors hence the two Hall sensors mounted in each electromagnet theoretically see the same magnetic flux density. This motivates averaging the Hall sensor signals the following way

$$
V_{H}=\frac{\left|V_{H, N}\right|+\left|V_{H, S}\right|}{2}
$$

where $N$ and $S$ denotes the north and south pole, respectively. Combining the two Hall sensor signals, reduces the complexity of the calibration procedure, and helps average out random noise in the resulting signal $V_{H}$. The force from a single electromagnet can be estimated using a quadratic relation [47]

$$
F_{m a g}=K_{a} V_{H}^{2}
$$

in which $F_{\text {mag }}$ is the estimated electromagnetic force, $K_{a}$ is a constant to be determined through calibration, and $V_{H}$ is the Hall sensor voltage signal. The force estimated as a function of the Hall sensor signals for an actuator consisting of two electromagnets (e.g. $E M_{1}$ and $E M_{3}$ ) can be represented as

$$
F_{a c t}=K_{b} V_{H, E M_{1}}^{2}-K_{c} V_{H, E M_{3}}^{2}
$$

in which $F_{a c t}$ is the exerted actuator force, $K_{b}$ and $K_{c}$ are two constants to be determined through calibration, and $V_{H, E M_{1}}$ and
$V_{H, E M_{3}}$ are the combined Hall sensor signals from $E M_{1}$ and $E M_{3}$ given by Eqn. (2). Each AMB features two actuators tilted $\pm 45^{\circ}$, respectively, from vertical and projecting the force from these onto the global reference system enables setting up the Free Body Diagram (FBD) presented in Fig. 11. In Fig. $11 F_{A, y}$ and $F_{A, z}$ represents the AMB forces from AMB A, $F_{B, y}$ and $F_{B, z}$ represents the AMB forces from AMB B, $F_{a p p, y}$ and $F_{a p p, z}$ are the forces applied through the calibration facility pistons, $F_{g}$ is the gravitational force from the shaft, $F_{c, y}$ and $F_{c, z}$ are the forces from the flexible coupling and $M_{c, y}$ and $M_{c, z}$ are moments acting on the shaft from the flexible coupling. Summing forces and moments applying the FBD of Fig. 11 result in four equations with eight unknowns, which are the calibration constants. These equations can be put on matrix form to yield a system of equations on the form $\mathbf{A x}=\mathbf{b}$ where the matrix $\mathbf{A}$ contains information of the Hall sensor signals, $\mathbf{x}$ is a vector containing the eight calibration constants and $\mathbf{b}$ is a vector of force components applied using the calibration facility. This equation system can be utilized to obtain the calibration constants from a large calibration dataset through a Least Squares scheme. However as the system is underdetermined, the result would be non-unique and the constants non-physical. To obtain a unique solution a constrained fitting scheme is used which effectively reduces the number of unknowns to four constants, one for each actuator. An equivalent representation of the resulting system of equations used in the Least Squares scheme is shown in Eqn. (3), where the last index $j$ of the Hall sensor voltages $V_{H, A M B, \text { actuator, } j}$ and applied force components $F_{\text {app,direction, }}$, denotes a specific load step of the included $n$ load steps. The factors $r_{A}$ and $r_{B}$ in the moment equations are length ratios. The result of a fitting is the four cal-

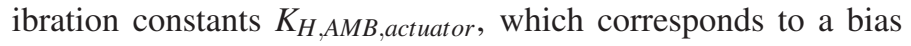
current and shaft position.

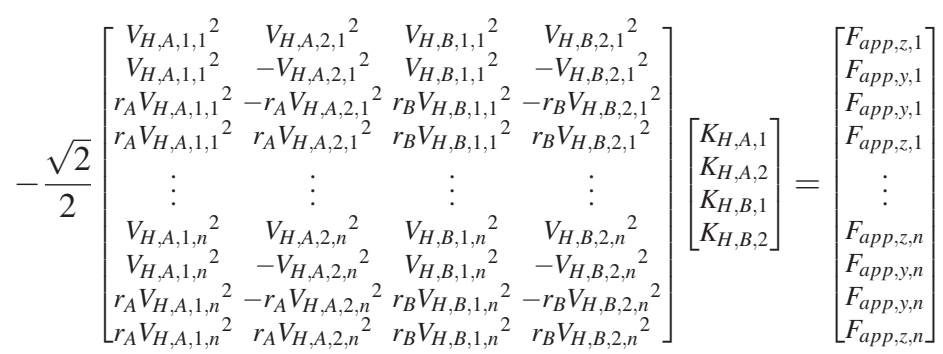

To evaluate if the constrained fitting imposes limitations on the precision of the force estimation, a comparison with the unconstrained equation system is performed and the results are included in the results section.

The calibration experiments are conducted for three choices of AMB bias currents $I_{\text {bias }}$ namely, $6 \mathrm{~A}, 8 \mathrm{~A}$, and $10 \mathrm{~A}$. For each choice of bias currents a range of forces applied by the individual pistons of the calibration facility are chosen. The force range is divided into a number of load steps of $250 \mathrm{~N}$. The 


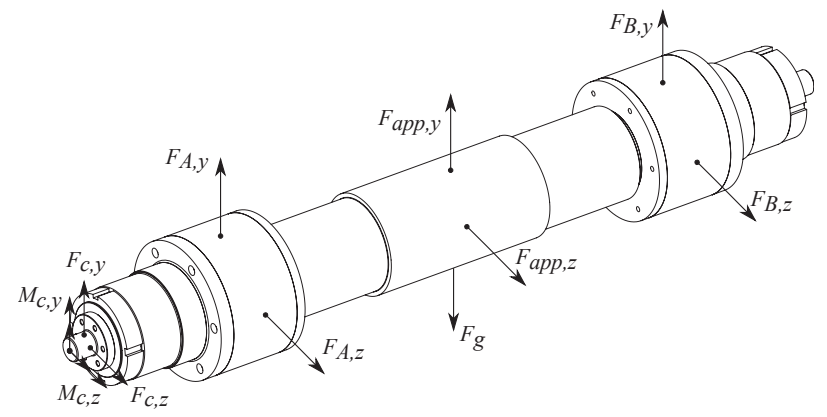

FIGURE 11: Free body diagram for the shaft during calibration

TABLE 4: Calibration experiment matrix

\begin{tabular}{lrr}
\hline$I_{\text {bias }}[\mathrm{A}]$ & Force range [N] & Load steps \\
6 & $0-2000$ & 17 \\
8 & $0-3000$ & 25 \\
10 & $0-4000$ & 33 \\
\hline
\end{tabular}

specifications for each calibration experiment are presented in Table 4. To capture the change in the calibration constants as a function of the position of the shaft, an array of different shaft positions are considered. The array expands a square domain of $9 \times 9$ positions separated by $5 \mu \mathrm{m}$ symmetrically around zero. This yields a position range from $[-20 ; 20] \mu \mathrm{m}$ in the $y$-direction and similarly in the $z$-direction, where $(0,0)$ indicates a centred shaft. This range is chosen to encompass the range of shaft positions needed for flow perturbation in the seal experiments.

For each choice of $I_{\text {bias }}$ a calibration cycle is conducted. The calibration cycle is illustrated in Fig. 12 and described in the following: One of the 81 positions in the envelope is chosen, and the shaft is positioned accordingly. A loading direction is specified and the chosen piston loops over the force range in the steps of $250 \mathrm{~N}$, first increasing the load towards its maximum value and then decreasing the load in steps towards zero. For each step in load, the control software waits until transients have died out before acquiring the sensor data. This process is repeated for all loading directions and thereby all pistons, and for all positions in the envelope. Subsequently the data is stored for post processing. The whole procedure is automated to reduce error and time consumption.

\section{Results of the calibration validation}

The calibration of the Hall sensor system is validated through data from a dedicated set of experiments obtained specifically for validation purposes. In these validation experiments the shaft

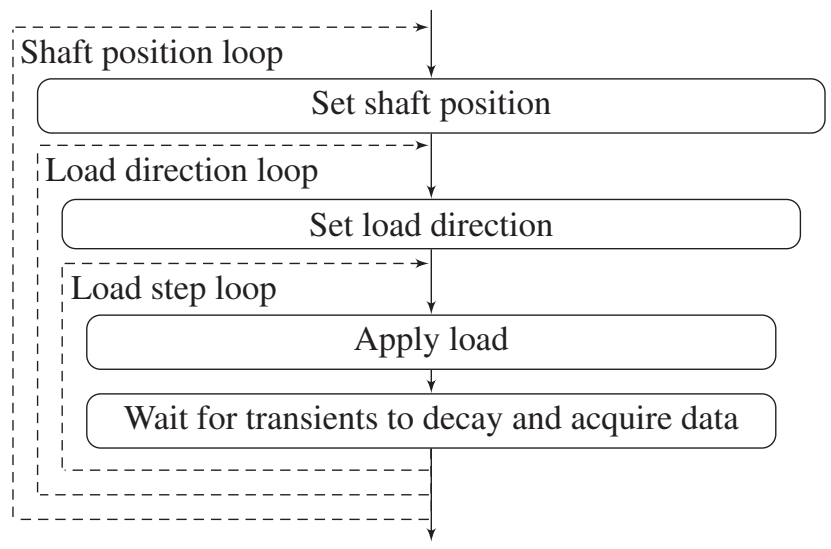

FIGURE 12: Flow chart for the automated calibration cycle

is loaded by the pneumatic pistons similar to the calibration method. Included are experiments with off-axis loading to quantify the force estimation capabilities in load directions that are not included in the calibration. The difference in force estimation performance of the constrained and unconstrained fitting scheme is investigated by comparison of errors. The force component error $u_{i}$ is calculated as

$$
u_{i}=F_{K_{H}, i}-F_{a p p, i}
$$

where $i$ denotes a force component ( $y$ or $z$ ). $F_{K_{H}, i}$ is the force component estimated by the calibrated Hall sensor system and $F_{a p p, i}$ is the force component measured by the force transducer at the piston. Examples of errors on the estimated force components for the constrained and unconstrained methods are shown in Fig. 13. Fig. 13a and 13b shows the error from an experiment with loading from a single piston in the positive horizontal direction. Fig. $13 \mathrm{c}$ and $13 \mathrm{~d}$ shows the error from an experiment where the shaft is loaded by two pistons yielding a resulting force $45^{\circ}$ from the vertical upwards direction. For illustrative purposes the force estimation error for the unloaded direction $F_{y}$ in the one piston experiment (Fig. 13a and 13b) is plotted as a function of the applied force $F_{a p p, z}$. The terms on-axis and off-axis loading refer to a resulting force in and not in the direction of a piston, respectively. The general tendency in the validation experiments is that the constrained and unconstrained fitting schemes yield similar errors for on-axis loading, but the unconstrained show larger errors for the off-axis loading. The constrained calibration gives more consistent results independent of load direction, hence it is more suitable for the testing of turbomachinery seals, where the ability to quantify cross coupled forces is of high importance. The following results are obtained utilizing the constrained method. 
TABLE 5: Validation experiment force errors for different force estimation methods and bias currents

\begin{tabular}{lccccccc}
\hline Method & \multicolumn{4}{c}{ Hall sensor } & \multicolumn{3}{c}{ Current/air gap } \\
\hline Bias current & {$[\mathrm{A}]$} & \multicolumn{1}{c}{6} & \multicolumn{1}{c}{8} & 10 & \multicolumn{1}{c}{6} & \multicolumn{1}{c}{8} & \multicolumn{1}{c}{10} \\
$F_{\text {res,max }}$ & {$[\mathrm{N}]$} & 1500 & 2250 & 3000 & 1500 & 2250 & 3000 \\
\hline MAE & {$[\mathrm{N}]$} & 11.6 & 17.6 & 25.7 & 32.7 & 56.7 & 81.9 \\
MAE/F $F_{\text {res,max }}$ & {$[\%]$} & 0.77 & 0.78 & 0.86 & 2.2 & 2.5 & 2.7 \\
Max. error & {$[\mathrm{N}]$} & 34.2 & 65.3 & 61.1 & 78.2 & 171 & 205 \\
Max. error $/ F_{\text {res,max }}[\%]$ & 2.3 & 2.9 & 2.0 & 5.2 & 7.6 & 6.8 \\
\hline
\end{tabular}

The obtained calibration constants $K_{H, A M B, \text { actuator }}$ for the shaft in a centred position can be seen for the different choices of bias currents in Fig. 14. As evident from Fig. 14 the calibration constants are dependent on the choice of bias current. The difference in the calibration constants between AMB A and B is expected due to production and assembly tolerances. The position dependence of the calibration constants is illustrated in Fig. 15, which shows surface plots of the four constants for $10 \mathrm{~A}$ bias current at the positions included in the calibration domain. In the domain limited to the range $[-20 ; 20] \mu \mathrm{m}$ the observed change in $K_{H}$ due to position is within $3 \%$.

The force estimated using the Hall sensor system is compared to the current/air gap force estimation in Table 5. The maximum error and Mean Absolute Error (MAE) from validation experiments are listed for the two methods at the different bias currents. The selected maximum resulting force $F_{\text {res,max }}$ for the experiments is increased with bias current. Note that the maximum error does not necessarily occur at the max. applied force. Table 5 is based on data from four on-axis and four off-axis loaded validation experiments for each bias current. The magnitude of the errors generally increases with the bias current. The force estimation errors arising from using the current/air gap method are more than twice as large as the estimation errors introduced by applying the Hall sensor system. As expected a more precise force estimation is obtained with the Hall sensors system than with the current/air gap method.

\section{Uncertainty quantification}

In order to ensure high-quality force estimation capabilities for the turbomachinery seal tests using the embedded Hall sensor system it is necessary to identify any uncertainties in the force estimation. The uncertainties are estimated by the Root-SumSquared (RSS) method as outlined in [48]. An uncertainty $u_{R}$ of
TABLE 6: Uncertainty of force components and contributing errors for different bias currents

\begin{tabular}{llrrr}
\hline Bias current & {$[\mathrm{A}]$} & \multicolumn{1}{c}{6} & \multicolumn{1}{c}{8} & \multicolumn{1}{c}{10} \\
\hline$u_{M A E}$ & {$[\mathrm{~N}]$} & 11.6 & 17.6 & 25.7 \\
$u_{\text {rep }}$ & {$[\mathrm{N}]$} & 0.1 & 0.1 & 1.1 \\
$u_{F T}$ & {$[\mathrm{~N}]$} & 0.39 & 0.42 & 0.45 \\
\hline$u_{F_{i}}$ & {$[\mathrm{~N}]$} & 11.6 & 17.6 & 25.7 \\
\hline
\end{tabular}

a quantity $R$ is estimated by the general equation

$$
u_{R}=\left[\left(\frac{\partial R}{\partial x_{1}} u_{1}\right)^{2}+\left(\frac{\partial R}{\partial x_{2}} u_{2}\right)^{2}+\ldots+\left(\frac{\partial R}{\partial x_{n}} u_{n}\right)^{2}\right]^{\frac{1}{2}}
$$

where $x_{1}, x_{2}, \ldots, x_{n}$ are the influencing variables with the corresponding errors $u_{1}, u_{2}, \ldots, u_{n}$. The significant contributors to the uncertainty of the force component are: (1) the error identified through the validation experiments $u_{M A E}$ shown in Table 5, (2) repeatability error $u_{\text {rep }}$ and (3) force transducer error $u_{F T}$. As these errors are directly influencing the force estimate, Eqn. (4) is reduced and the uncertainty of the force components becomes

$$
u_{F_{i}}=\left[\left(u_{M A E}\right)^{2}+\left(u_{r e p}\right)^{2}+\left(u_{F T}\right)^{2}\right]^{\frac{1}{2}}
$$

The values of the calculated errors along with the final uncertainty are found in Table 6 for the different bias currents.

\section{Conclusion}

The main design considerations for and the functionality of the three modules of the full industrial scale state of the art multiphase turbomachinery seal test facility have been described. The AMB based test facility is able to support and excite the shaft without mechanical contact while the embedded Hall sensor system allows for precise contact-free force estimation. In order to achieve the force estimation precision needed for identification of seal properties, the Hall sensor system requires calibration. The methodology of the Hall sensor system calibration is presented along with results from force estimation validation experiments. The force estimation precision obtained using the Hall sensor system is compared to the conventional force estimation technique enabled through current/air gap measurements. The Hall sensor based force estimation method outperforms the conventional current/air methodology as expected, and exhibits mean absolute estimation errors in the order of $1 \%$ of the maximum force applied in the validation experiments conducted. The 


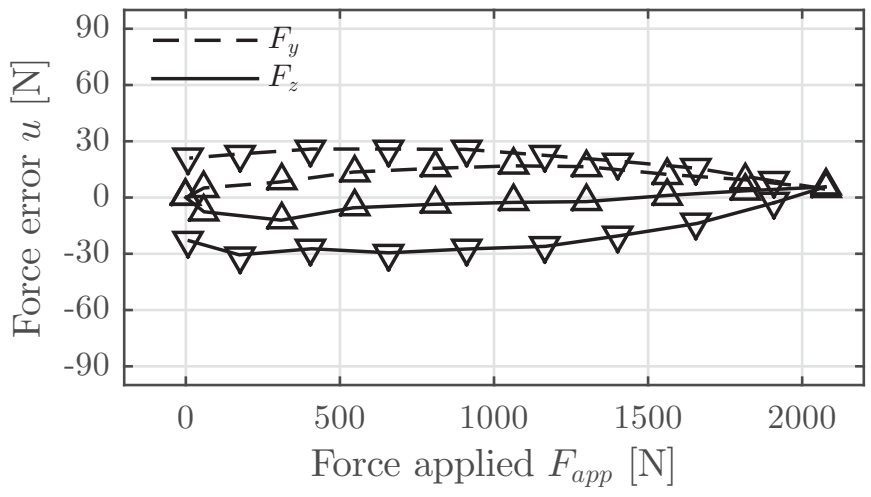

(a) Constrained fitting - one piston loading $(+\mathrm{z})$

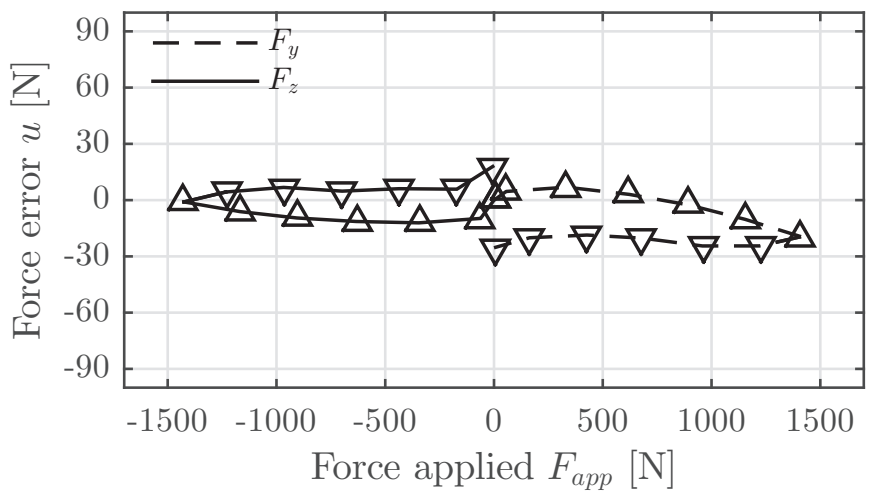

(c) Constrained fitting - two piston loading $(+\mathrm{y},-\mathrm{z})$

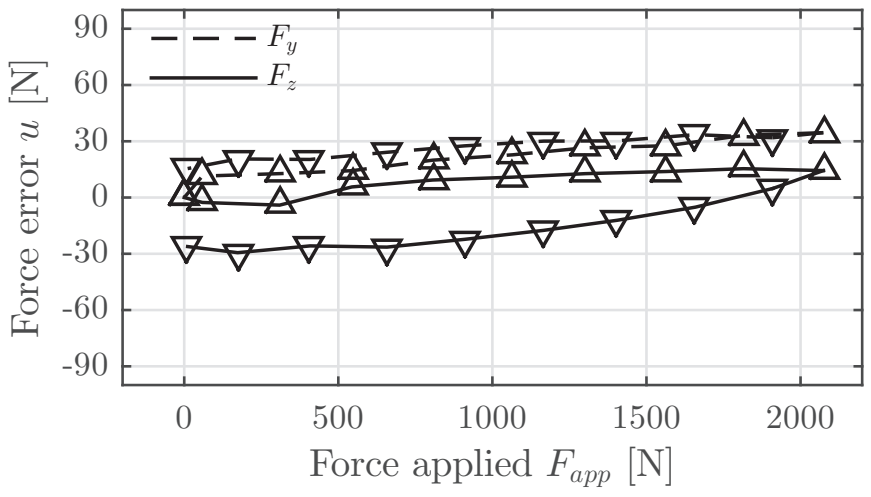

(b) Unconstrained fitting - one piston loading $(+\mathrm{z})$

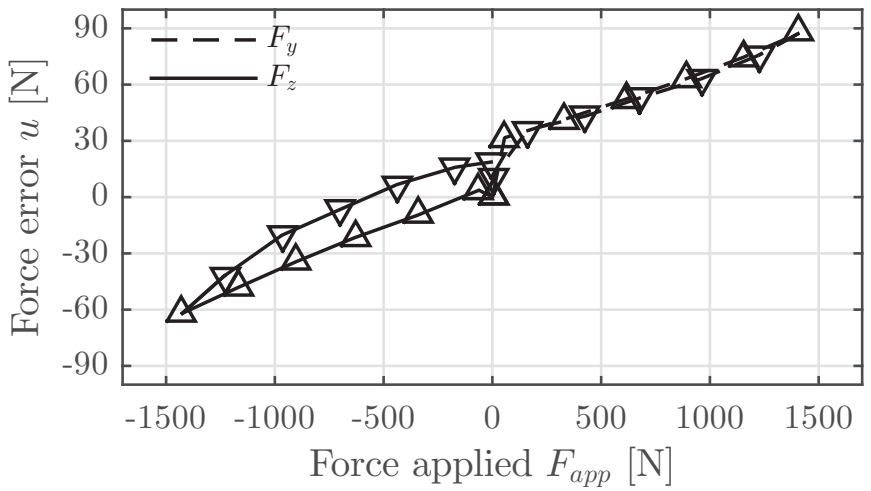

(d) Unconstrained fitting - two piston loading $(+\mathrm{y},-\mathrm{z})$

FIGURE 13: Examples of force component errors for validation experiments for the two fitting methods. 8 A bias current and centred shaft. upwards and downwards pointing triangles mark increasing and decreasing loads, respectively

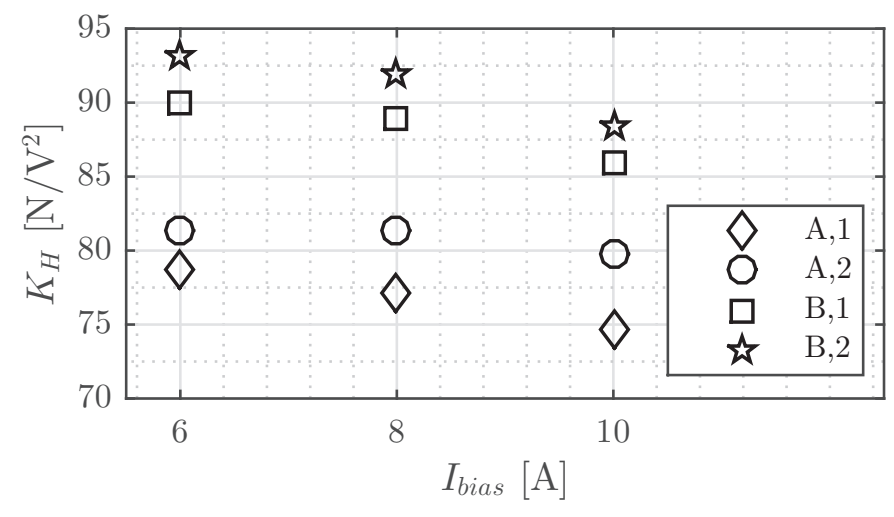

FIGURE 14: Calibration constants for centred shaft at different bias currents

uncertainty on the force estimation is addressed through an uncertainty quantification based on the RSS methodology.

\section{REFERENCES}

[1] Santos, I. F., and Russo, F. H., 1998. "Tilting-Pad Journal Bearings With Electronic Radial Oil Injection". Journal of Tribology, 120(3), pp. 583-594.

[2] Santos, I., and Nicoletti, R., 1999. "THD Analysis in Tilting-Pad Journal Bearings Using Multiple Orifice Hybrid Lubrication". October, 121(October), pp. 892-900.

[3] Childs, D., 1993. Turbomachinery Rotordynamics: Phenomena, Modeling, and Analysis. John Wiley \& Sons, Inc., Hoboken, New Jersey.

[4] Childs, D., and Vance, J., 1997. "Annular Gas Seals and Rotordynamics of Compressors and Turbines". In Proceedings of the Twenty-Sixth Turbomacinery Symposium, pp. 201-220.

[5] Moore, J. J., 2003. "Three-Dimensional CFD Rotordynamic Analysis of Gas Labyrinth Seals". Journal of Vibration and Acoustics, 125(4), pp. 427-433.

[6] Ertas, B. H., Gamal, A., and Vance, J. M., 2006. "Rotordynamic Force Coefficients of Pocket Damper Seals". ASME 


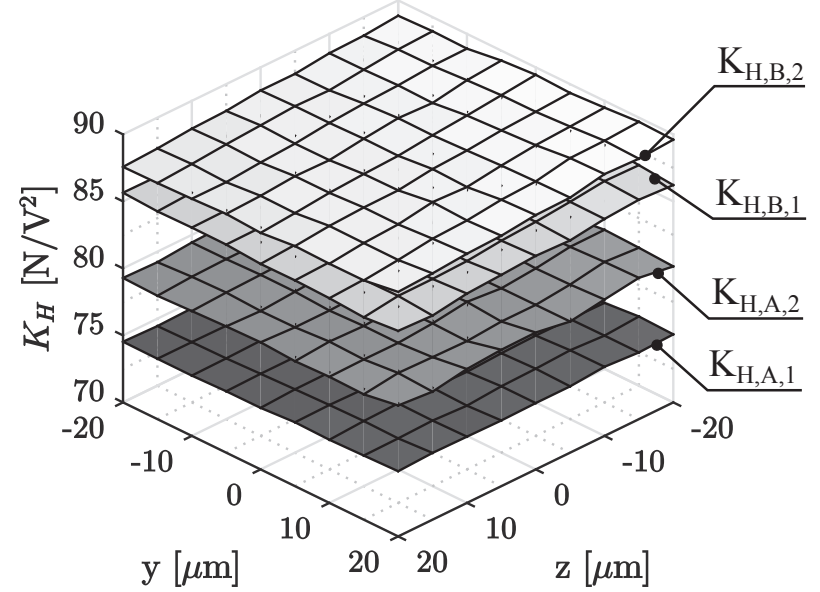

FIGURE 15: Calibration constants at different shaft positions. $10 \mathrm{~A}$ bias current

Journal of Turbomachinery, pp. 725-737.

[7] Childs, D. W., 1983. "Dynamic Analysis of Turbulent Annular Seals Based on Hirs Lubrication Equations". Journal of Lubrication Technology, 105, pp. 429-436.

[8] Nelson, C., Childs, D., Nicks, C., and Elrod, D., 1986. "Theory Versus Experiment for the Rotordynamic Coefficients of Annular Gas Seals, Part 2: Constant-Clearance and Convergent-Tapered Geometry". Journal of Tribology, pp. 433-438.

[9] Murphy, B. T., and Vance, J. M., 1980. "Labyrinth Seal Effects on Rotor Whirl Stability". In Proceedings of the Second International Conference on Vibrations in Rotating Machinery.

[10] Hsu, Y., and Brennen, C. E., 2002. "Fluid Flow Equations for Rotordynamic Flows in Seals and Leakage Paths". Journal of Fluids Engineering, 124(1), pp. 176-181.

[11] Zeidan, F. Y., Perez, R. X., and Stephenson, E. M., 1993. "The Use of Honeycomb Seals in Stabilizing Two Centrifugal Compressors". In Proceedings of the Twenty-Second Turbomacinery Symposium, pp. 3-16.

[12] Childs, D. W., Rodriguez, L. E., Cullotta, V., Al-Ghasem, A., and Graviss, M., 2006. "Rotordynamic-Coefficients and Static (Equilibrium Loci and Leakage) Characteristics for Short, Laminar-Flow Annular Seals". Journal of Tribology, 128(2), pp. 378-387.

[13] Picardo, A., and Childs, D. W., 2005. "Rotordynamic Coefficients for a Tooth-on-Stator Labyrinth Seal at 70 Bar Supply Pressures: Measurements Versus Theory and Comparisons to a Hole-Pattern Stator Seal". Journal of Engineering for Gas Turbines and Power, 127(4), pp. 843-855.

[14] Childs, D. W., and Wade, J., 2004. "RotordynamicCoefficient and Leakage Characteristics for Hole-Pattern-
Stator Annular Gas SealsMeasurements Versus Predictions". Journal of Tribology, 126(2), pp. 326-333.

[15] Ertas, B. H., Delgado, A., and Vannini, G., 2011. "Rotordynamic Force Coefficients for Three Types of Annular Gas Seals with Inlet Preswirl and High Differential Pressure Ratio". Proceedings of ASME Turbo Expo 2011: Power for Land, Sea and Air(518), pp. 1-12.

[16] Hirano, T., Guo, Z., and Kirk, R. G., 2005. "Application of Computational Fluid Dynamics Analysis for Rotating MachineryPart II: Labyrinth Seal Analysis". Journal of Engineering for Gas Turbines and Power, 127(4), pp. 820-826.

[17] Athevale, M. M., Przekwas, A. J., Hendricks, R. C., and Liang, A., 1994. "SCISEAL: A 3D CFD Code for Accurate Analysis of Fluid Flow and Forces in Seals". In Proceedings of the Advanced ETO Propulsion Conference, pp. 337-345.

[18] Moore, J. J., and Palazzolo, A. B., 1999. “CFD Comparison to 3D Laser Anemometer and Rotordynamic Force Measurements for Grooved Liquid Annular Seals". ASME J. Tribol., 121(2), pp. 307-314.

[19] Kim, N., and Rhode, D. L., 2000. "A New CFDPerturbation Model For The Rotordynamics of Incompressible Flow Seals". In ASME International Gas Turbine and Aeroengine Congress and Exposition.

[20] Nordmann, R., and Dietzen, F. J., 1988. Finite Difference Analysis of Rotordynamic Seal Coefficients For An Eccentric Shaft Position.

[21] Rhode, D. L., Hensel, S. J., and Guidry, M. J., 1992. "Labyrinth Seal Rotordynamic Forces Using a ThreeDimensional Navier-Stokes Code". ASME J. Tribol.(114), pp. 683-689.

[22] Tam, L. T., Przekwas, A. J., Muszynska, A., Hendricks, R. C., Braun, M. J., and Mullen, R. L., 1988. "Numerical and Analytical Study of Fluid Dynamic Forces in Seals and Bearings". ASME J. Vibr. Acoust., 110, pp. 315-325.

[23] Nielsen, K. K., Childs, D. W., and Myllerup, C. M., 2001. "Experimental and Theoretical Comparison of Two Swirl Brake Designs". Journal of Turbomachinery, 123(2), p. 353.

[24] Nielsen, K. K., Myllerup, C. M., and Van den Braembussche, R. A., 1999. "Parametric Study of the Flow in Swirl Brakes by Means of a 3D Navier- Stokes Solver". In Transactions of the Third European Conference on Turbomachinery, pp. 489-498.

[25] Nielsen, K. K., Van den Braembussche, R., and Myllerup, C., 1998. "Optimization of swirl brakes by means of a 3D Navier-Stokes solver". In The 1998 International Gas Turbine \& Aeroengine Congress \& Exhibition, p. 7.

[26] Nielsen, K. K., Jønck, K., and Underbakke, H., 2012. HolePattern and Honeycomb Seals Rotordynamic Forces: Validation of CFD Based Prediction Techniques.

[27] Wagner, N., Steff, K., Gausmann, R., and Schmidt, M., 
2009. "Investigations on the Dynamic Coefficients of Impeller Eye Labyrinth Seals". Proceedings of the Thirtyeighth Turbomacinery Symposium.

[28] Kocur, J. A., Nicholas, J. C., and Lee, C. C., 2007. "Surveying Tilting Pad Journal Bearing and Gas Labyrinth Seal Coefficients and Their Effect on Rotor Stability". In Proceedings of the 36th Turbomachinery Symposium, pp. 110.

[29] Crowe, C. T., 2006. Multiphase flow handbook. CRC.

[30] Andrés, L. S., 2010. A Mixture Bulk-Flow Model for Anullar Pressure Seals. Tech. rep., Texas A\&M University, Mechanical Engineering Department, Turbomachinery Laboratory.

[31] Andrés, L. S., 2011. "Rotordynamic Force Coefficients of Bubbly Mixture Annular Pressure Seals". Proceedings of ASME Turbo Expo 2011, 60, pp. 1-10.

[32] Andrés, L. S., Lu, X., and Liu, Q., 2015. "Measurements Of Flowrate And Force Coefficients In A Short Length Annular Seal Supplied With A Liquid/Gas Mixture (Stationary Journal)". Tribology Transactions, 2004(November), pp. 00-00.

[33] Vannini, G., Bertoner, M., Nielsen, K. K., Stronach, R., Iudiciani, P., and Bertoneri, M., 2015. "Gt2015-43095 Experimental Results and Cfd Simulations of Labyrinth and Pocket Damper Seals for Wet Gas Compression". Proceedings of ASME Turbo Expo: Turbine Technical Conference and Exposition, pp. 1-13.

[34] Mihai, A., Abdelmalik, Z., and Gérard PINEAU, P., 2011. "Rotordynamic Analysis of Textured Annular Seals With Multiphase (Bubbly) Flow". Incas Bulletin, 3(3), pp. 313.

[35] Voigt, A. J., Iudiciani, P., Nielsen, K. K., and Santos, I. F., 2016. "CFD Applied for the Identification of Stiffness and Damping Properties for Smooth Annular Turbomachinery Seals in Multiphase Flow". In Submitted to ASME Turbo Expo 2016.

[36] Athavale, M., Przekwas, A., and Hendricks, R., 1992. "A Finite Volume Numerical Method to Calculate Fluid Forces and Rotordynamic Coefficients in Seals". 28th Joint Propulsion Conference and Exhibit.

[37] Chochua, G., and Soulas, T., 2007. "Numerical modeling of rotordynamic coefficients for deliberately roughened stator gas annular seals". Journal of tribology.

[38] Yan, X., Li, J., and Feng, Z., 2011. "Investigations on the Rotordynamic Characteristics of a Hole-Pattern Seal Using Transient CFD and Periodic Circular Orbit Model". Journal of Vibration and Acoustics, 133(4), aug, p. 041007.

[39] G., S., and E., M., 2009. Magnetic bearings theory, design, and application to rotating machinery. Springer, Dordrecht New York.

[40] Aenis, M., Knopf, E., and Nordmann, R., 2002. "Active Magnetic Bearings for the Identification and Fault Diagno- sis in Turbomachinery". Mechatronics, 12, pp. 1011-1021.

[41] Voigt, A., and Santos, I., 2012. "Theoretical and Experimental Investigation of Force Estimation Errors Using Active Magnetic Bearings with Embedded Hall Sensors". ASME Turbo Expo 2012.

[42] Zutavern, Z. S., and Childs, D. W., 2005. "Fiber-Optic Strain Gauge Calibration and Dynamic Flexibility Transfer Function Identification in Magnetic Bearings". Volume 4: Turbo Expo 2005, pp. 757-762.

[43] Raymer, S. G., and Childs, D. W., 2001. "Force Measurements in Magnetic Bearings Using Fiber Optic Strain Gauges". In ASME Turbo Expo 2001: Power for Land, Sea, and Air.

[44] Zutavern, Z. S., and Childs, D. W., 2008. "Identification of Rotordynamic Forces in a Flexible Rotor System Using Magnetic Bearings". Journal of Engineering for Gas Turbines and Power, 130(2), p. 022504.

[45] Kjolhede, K., and Santos, I. F., 2007. "Experimental Contribution to High-Precision Characterization of Magnetic Forces in Active Magnetic Bearings". Journal of Engineering for Gas Turbines and Power, 129(2), p. 503.

[46] Schweitzer, G., 2009. "Applications and Research Topics for Active Magnetic Bearings". In Proc. IUTAM-Symp. on Emerging Trends in Rotor Dynamics, pp. 1-11.

[47] Gähler, C., and Förch, P., 1994. "A Precise Magnetic Bearing Exciter for Rotordynamic Experiments". 4th International Symposium on Magnetic Bearings(August), pp. 193200.

[48] Moffat, R. J., 1988. "Describing the uncertainties in experimental results". Experimental Thermal and Fluid Science, 1(1), pp. 3-17. 